\title{
EXAMINATION OF BULL SEMEN AND OF THE BULL AND RABBIT TESTIS FOR THE PRESENCE OF CREATINE PHOSPHATE AND ARGININE PHOSPHATE
}

\author{
D. E. BROOKS \\ Agricultural Research Council, Unit of Reproductive Physiology and Biochemistry, \\ University of Cambridge*
}

(Received 19th February 1971)

There has been considerable controversy regarding the existence of phosphagens, such as creatine phosphate and arginine phosphate, in mammalian spermatozoa, though it is well documented that creatine phosphate forms a normal constituent of the testis (Treskin, 1872; Eggleton \& Eggleton, 1929; Ennor \& Rosenberg, 1952; White \& Griffiths, 1958). Wajzer \& Brochart (1947) were the first to claim that creatine phosphate and arginine phosphate were present in the 'sperme' of the boar. Later, Newton \& Rothschild (1961) reported that bull semen contains labile phosphorus and attributed this, at least in part, to creatine phosphate, though White \& Griffiths (1958), in a study involving both the spermatozoa and seminal plasma of a number of mammalian species (including the bull), were unable either to isolate phosphagens by a barium fractionation procedure or to demonstrate the appropriate guanidine kinases. On the other hand, there is good evidence for the occurrence of phosphagens in the spermatozoa of certain invertebrates. In two species of seaurchins, Yanagisawa (1959) found creatine phosphate in the spermatozoa, and arginine phosphate in the eggs, and quite recently, Brooks, Lutwak-Mann, Mann \& Martin (1971) demonstrated large amounts of arginine phosphate in octopus spermatozoa.

The present study was undertaken to obtain a more definite answer to the question of whether mammalian semen contains either creatine phosphate or arginine phosphate and, as an alternative approach to previous investigations, the experiments were designed to separate these phosphagens by chromatography on Dowex resin. Bull semen was collected by artificial vagina and extracted with an equal volume of $20 \%$ trichloroacetic acid (TCA) by methods based on those recently elaborated by Brooks (1970a) for the determination of adenine nucleotides. The semen was either added directly to ice-cold TGA in a centrifuge tube (Method I) or was first frozen in liquid $\mathrm{N}_{2}$ and then ground with frozen TGA until the sample thawed (Method II). The testes of a mature bull and rabbit were sliced and frozen in liquid $\mathrm{N}_{2}$ immediately after slaughter and were extracted by Method II. The extracts from semen and testes were centrifuged at $35,000 \mathrm{~g}$ for $5 \mathrm{~min}$ at $-2^{\circ} \mathrm{C}$. In order to minimize the breakdown of phosphagens, all following manipulations were carried out in a room main-

* Postal address: Animal Research Station, 307 Huntingdon Road, Cambridge CB3 OJQ. 
tained at $2^{\circ} \mathrm{C}$. The supernatant was quickly shaken with an equal volume of ether, six times, to remove TCA and neutralized with $1 \% \mathrm{NH}_{4} \mathrm{OH}$. The material was then passed on to a $0.6 \times 20-\mathrm{cm}$ column of Dowex AG1X2 (200 to 400 mesh in the formate form) and the column was washed through with water until the effluent had a basal absorption at $254 \mathrm{~nm}$. The column was eluted at 21.6 $\mathrm{ml} / \mathrm{hr}$ (3.6-ml fractions) with a gradient of formic acid formed by $50 \mathrm{ml}$ of water in the mixing chamber and $50 \mathrm{ml}$ of $4 \mathrm{M}$-formic acid in the reservoir. In some instances, the neutralized extract was subjected to ultrafiltration in a pressure dialysis cell before it was applied to the column of Dowex 1 (Brooks, 1970b).

TABLE 1

RECOVERY OF GREATINE PHOSPHATE AND ARGININE PHOSPHATE

\begin{tabular}{l|c|c}
\hline \multicolumn{1}{c|}{ Material } & $\begin{array}{c}\text { Extraction } \\
\text { method }\end{array}$ & $\begin{array}{c}\% \text { Recovery of } \\
\text { phosphagen }\end{array}$ \\
\hline CP added directly to column & & 100 \\
AP added directly to column & & 100 \\
CP in 5 ml of water & I & 80 \\
10 ml seminal plasma + CP & I & 80 \\
$6 \mathrm{ml}$ semen + GP & I & 84 \\
$6 \mathrm{ml}$ semen + GP & I & 80 \\
$4.5 \mathrm{ml}$ semen +AP & II & 86 \\
5 ml semen +AP & & 82 \\
Average recovery & & \\
\hline
\end{tabular}

$\mathrm{CP}=$ creatine phosphate, $\mathrm{AP}=$ arginine phosphate.

In the extraction and chromatographic procedures described in the text, $2.75 \mu \mathrm{mol}$ of CP and $0.495 \mu \mathrm{mol}$ of AP were added to the acid (20\% TCA) immediately before the addition of semen.

In order to test for the presence of creatine phosphate and arginine phosphate, $0 \cdot 5-\mathrm{ml}$ samples taken from the column fractions were made $0 \cdot 1 \mathrm{M}$ with respect to $\mathrm{HCl}$ and heated at $65^{\circ} \mathrm{C}$ for $9 \mathrm{~min}$ in order to hydrolyse the phosphagens (Ennor \& Rosenberg, 1952). The samples were then analysed for inorganic phosphate by the micromethod of Berenblum \& Chain (1938) and for free guanidines by the method of Rosenberg, Ennor \& Morrison (1956) in a final volume of $1 \mathrm{ml}$.

The sodium salt of arginine phosphate was prepared from the barium salt by shaking a solution with a little Dowex AG50WX8 (100 to 200 mesh in the $\mathrm{Na}^{+}$form). Good recoveries of both phosphagens were obtained when the standards were carried through the complete procedure (Table 1).

Under the chromatography conditions used, arginine phosphate was eluted before AMP, and creatine phosphate was eluted between AMP and inorganic phosphate. It was found that some material of high molecular weight, which was derived from seminal plasma, was not precipitated by TCA and was eluted at the position of arginine phosphate during chromatography. This material gave a positive reaction for arginine and interfered in the colorimetric determination 
of inorganic phosphate by forming a precipitate on the addition of 2-methylpropan-1-ol; this interference was removed by submitting the extract to ultrafiltration before chromatography (Text-fig. 1).

Despite good recoveries of the added standards of creatine phosphate and arginine phosphate (Table 1), neither of these phosphagens could be detected in a series of twelve ejaculates (average volume of $7.2 \mathrm{ml}$ and average sperm concentration of $1.1 \times 10^{9} / \mathrm{ml}$ ). On the other hand, using the same procedure,

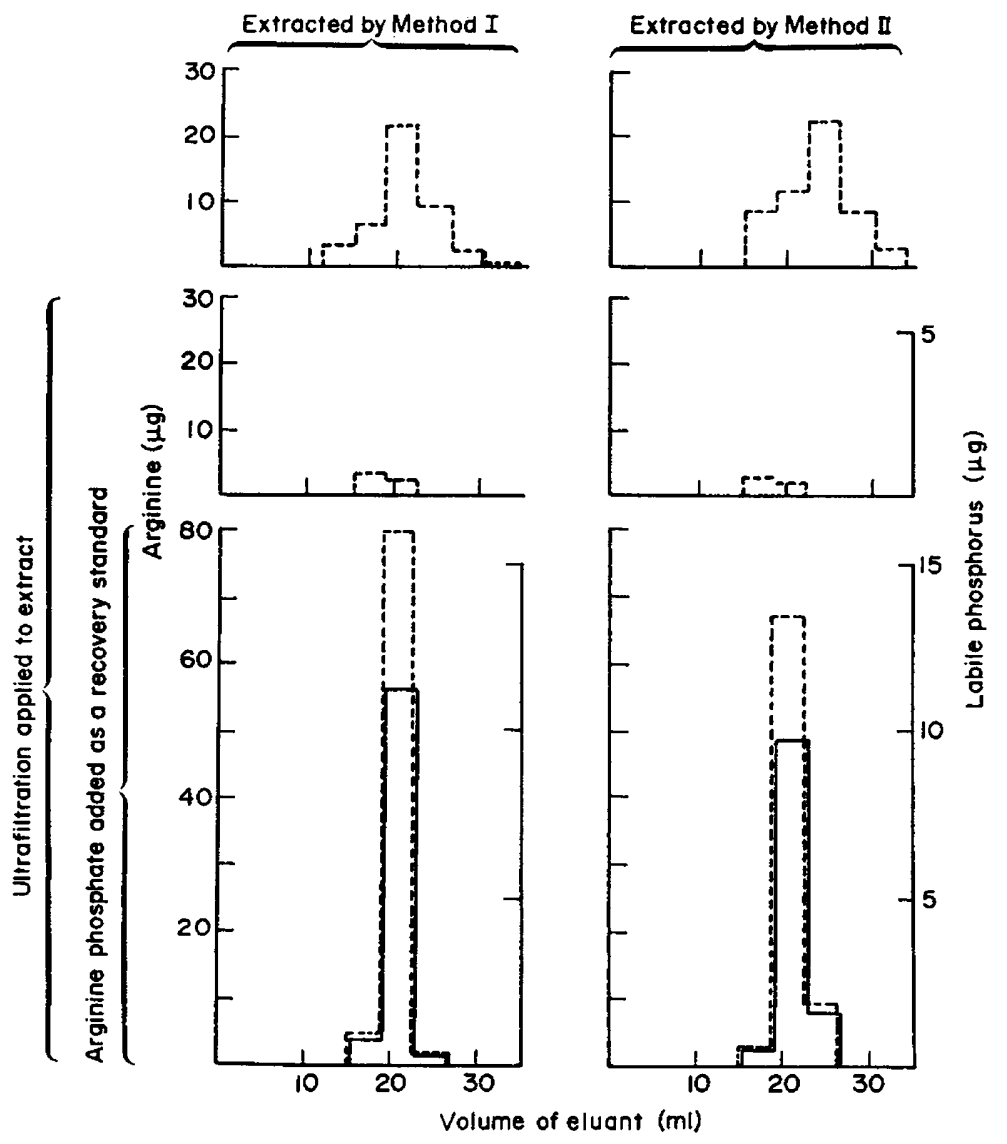

Text-Fig. 1. Chromatography of extracts from freshly ejaculated bull semen (average volume of $6.3 \mathrm{ml}$ and average sperm concentration of $\left.0.9 \times 10^{9} / \mathrm{ml}\right) .----$, Arginine; , labile phosphorus.

creatine phosphate was demonstrated without any difficulty in both bull and rabbit testes, which contained 102 and $206 \mathrm{nmol} / \mathrm{g}$ fresh weight, respectively. If spermatozoa did contain creatine phosphate or arginine phosphate, they should have been readily detected by the methods employed, which were sufficiently sensitive to detect as little as $10 \mathrm{nmol} / 10^{9}$ spermatozoa. The possibility that bull semen may contain labile phosphorous compounds other than these two phosphagens still remains to be investigated. 
Standard creatine phosphate (disodium salt) was obtained from the Boehringer Corp. and a sample of arginine phosphate (barium salt) was kindly donated by Professor H. Rosenberg and Dr J. F. Morrison (Australian National University).

\section{REFERENCES}

Berenblum, I. \& Ghain, E. (1938) XL. An improved method for the colorimetric determination of phosphate. Biochem. F. 32, 295.

Brooks, D. E. (1970a) Observations on the content of ATP and ADP in bull spermatozoa using the firefly luciferase system. 7. Reprod. Fert. 23, 525.

BROoks, D. E. (1970b) Acid-soluble phosphorus compounds in mammalian semen. Biochem. 7. 118, 851.

Brooks, D. E., Lutwak-Mann, C., ManN, T. \& Martin, A. W., Jr (1971) Motility and energy-rich phosphorus compounds in spermatozoa of Octopus dofleini martini. Proc. $R$. Soc. B (in press).

Eggleton, G. P. \& Eggleton, P. (1929) A method of estimating phosphagen and some other phosphorus compounds in muscle tissue. 7. Physiol., Lond. 68, 193.

Ennor, A. H. \& Rosenberg, H. (1952) The determination and distribution of phosphocreatine in animal tissues. Biochem. F. 51, 606.

Newton, A. A. \& Rothschild, LoRd (1961) Energy-rich phosphate compounds in bull semen: comparison of their metabolism with anaerobic heat production and impedance change frequency. Proc. R. Soc. B, 155, 183.

Rosenberg, H., Ennor, A. H. \& Morrison, J. F. (1956) The estimation of arginine. Biochem. 7.63, 153.

Treskin (1872) Die Bestand theile der Testikel. Chemische Untersuchung. Pflüg. Arch. ges. Physiol. $5,122$.

Wajzer, J. \& Brochart, M. (1947) Présence de la phosphoarginine dans les spermatozoïdes de Mammifères. C. r. hebd. Séanc. Acad. Sci., Paris, 225, 965.

Whire, I. G. \& Grifriths, D. E. (1958) Guanidines and phosphagens of semen. Aust. J. exp. Biol. med. Sci. 36, 97.

YanagisawA, T. (1959) Studies on Echinoderm phosphagens. I. Occurrence and nature of phosphagens in sea-urchin eggs and spermatozoa. 7. Fac. Sci. Tokyo Univ. IV, 8, 473. 